\title{
THE IMPACT OF SINTERING PROCESS PARAMETERS ON DENSITY OF PARTS PRODUCED BY METAL INJECTION MOULDING (MIM)
}

\section{PRAVEEN PACHAURI}

Professor, Department of Mechanical Engineering, Noida Institute of Engineering \& Technology, Greater Noida-201306, India

\begin{abstract}
The identification of significant process parameters during sintering of brown parts in Metal Injection Moulding (MIM) is essential because improper control of these parameters can result poor parts. The controlled parameters used for optimization in this work include sintering temperature, heating rate, sintering time, cooling rate and sintering atmosphere. These parameters had been optimized using analysis of variance (ANOVA) for signal to noise ratios obtained in experiment performed by following Taguchi $L_{16}$ orthogonal array. The ANOVA was used to obtain the contribution of significant process parameters for final density of parts. Results showed that four out of the five factors were the significant factors. The sintering temperature had a contribution of $14.37 \%$ at a confidence level of $95 \%$, heating rate had a contribution of $14.65 \%$ at a confidence level of $95 \%$, sintering time had a contribution of $59.58 \%$ at a confidence level of 99\%, cooling rate had a contribution of $10.70 \%$ with a confidence level of $95 \%$, and sintering atmosphere was observed to be insignificant factor for final density attained by the specimen.
\end{abstract}

KEYWORDS: Analysis of Variance (ANOVA); Orthogonal Array; Metal Injection Moulding (MIM); Sintering

Received: Jun 08, 2020; Accepted: Jun 28, 2020; Published: Sep 10, 2020; Paper Id.: IJMPERDJUN20201146

\section{INTRODUCTION}

Metal Injection Moulding (MIM) is one of the promising technologies to process metal powders into parts of desired shapes. The MIM process incorporates the traditional shape-making capability of plastic injection moulding and materials flexibility of powder metallurgy [1]. The process consists of four main steps: mixing, injection moulding, debinding and sintering. In the mixing step, the powder is mixed with a binder to form a homogeneous feedstock. The binder is key component, which caters the necessary flowability and formability for moulding [2]. During injection moulding a green part with the desired shape is formed by the feedstock flow into a mold under pressure. After moulding, the binder holds the particles in place. The binder is then withdrawn in the debinding step and the debound brown part is sintered to achieve the required mechanical properties. The geometrical accuracy and mechanical properties of the final parts after sintering depend strongly on the process parameters in the different stages [3,4]. The classical design of experiment (DOE) technique has been used by many authors [5-7] for the sake of optimization of single process parameters at a time. In order to obtain high efficiency in the planning and analysis of experimental data, the Taguchi method is recognized as a systematic approach for design and analysis of experiments to improve the product quality. This method has been applied by many authors to investigate and optimize the process parameters [8-13]. The success of MIM process is highly dependent on sintering process [1621]. The main objective of this paper is to optimize the sintering process parameters to attain high density of final parts. 


\section{MATERIALS AND METHODS}

To make the working material, the SS316L stainless steel powder was mixed with the binder comprised of polyethylene glycol (PEG), polymethyl methacrylate (PMMA), paraffin wax and stearic acid (SA) to form the feedstock for moulding. The main advantage and utility of using PMMA/PEG binder is that it can be removed from the mouldings in a comparatively short time. The SS316L metal powder used in this research was supplied by Osprey®. The chemical composition of the steel powder used is presented in Table 1. The particle size distribution of metal powder is given in Table 2. The percentage concentration of constituents by weight and densities are presented in Table 3 . The details of the binder ingredients are given in Table 4.

Table 1: Composition of SS316 L Powder (Report given by Osprey® along with the Powder)

\begin{tabular}{|c|c|c|c|c|c|c|c|c|}
\hline \multicolumn{9}{|c|}{ Element \% } \\
\hline $\mathbf{C}$ & $\mathbf{S i}$ & $\mathbf{M n}$ & $\mathbf{P}$ & $\mathbf{S}$ & $\mathbf{C r}$ & $\mathbf{N i}$ & $\mathbf{M o}$ & $\mathbf{F e}$ \\
\hline 0.018 & 0.55 & 1.5 & 0.031 & 0.017 & 16.9 & 11.6 & 2.2 & balance \\
\hline
\end{tabular}

Table 2: Size Distribution of SS316 L Powder (Report given by Osprey®)

\begin{tabular}{|c|c|c|c|c|}
\hline \multicolumn{5}{|c|}{ Powder Tests Report by Sandvik Osprey Ltd. } \\
\hline d10 & $\mathbf{d 5 0}$ & $\mathbf{d 9 0}$ & $\mathbf{- 5 3} \boldsymbol{\mu m}$ & Tap Density \\
\hline $3.9 \mu \mathrm{m}$ & $13.0 \mu \mathrm{m}$ & $36.6 \mu \mathrm{m}$ & $99.2 \%$ & $5.0 \mathrm{gm} / \mathrm{cc}$ \\
\hline
\end{tabular}

Table 3: Theoretical Density of Constituents of SS316 L Powder

\begin{tabular}{|c|c|c|}
\hline Element & Percentage Concentration & Theoretical Density \\
\hline $\mathrm{C}$ & 0.018 & 2.267 \\
\hline $\mathrm{Si}$ & 0.55 & 2.33 \\
\hline $\mathrm{Mn}$ & 1.5 & 7.47 \\
\hline $\mathrm{P}$ & 0.031 & 1.823 \\
\hline $\mathrm{S}$ & 0.017 & 1.96 \\
\hline $\mathrm{Cr}$ & 16.9 & 7.14 \\
\hline $\mathrm{Ni}$ & 11.6 & 8.9 \\
\hline $\mathrm{Mo}$ & 2.2 & 10.28 \\
\hline $\mathrm{Fe}$ & 67.184 & 7.874 \\
\hline $\mathrm{SS} \mathrm{316} \mathrm{L}$ & 100 & 7.88146 \\
\hline
\end{tabular}

Table 4: The Binder Ingredients

\begin{tabular}{|l|l|c|c|c|c|}
\hline \multicolumn{1}{|c|}{ Designation } & \multicolumn{1}{|c|}{ Manufacturer } & $\begin{array}{c}\text { Amount } \\
(\boldsymbol{\%})\end{array}$ & $\begin{array}{c}\text { Melting } \\
\text { point }{ }^{\circ} \mathbf{C}\end{array}$ & $\begin{array}{c}\text { Boiling } \\
\text { point }{ }^{\circ} \mathbf{C}\end{array}$ & $\begin{array}{c}\text { Density } \\
\text { (gm/cc) }\end{array}$ \\
\hline $\begin{array}{l}\text { Polymethyl Methacrylate } \\
\text { (PMMA) }\end{array}$ & Vetec & 65 & 157.77 & 200 & 1.19 \\
\hline Polyethylene Glycol (PEG) & Rankem & 08 & $35-40$ & 250 & 1.22 \\
\hline Paraffin Wax & Thermo Fischer Scientific & 25 & $60-62$ & 370 & 0.90 \\
\hline Stearic acid (SA) & Thermo Fischer Scientific & 02 & 70.1 & 383 & 0.94 \\
\hline
\end{tabular}

\section{Feedstock Formulation}

Both the metal powder and binder were mixed thoroughly for 90 minutes with the help of a Brookfield Rheometer in the desired proportion under precise weight and temperature control condition. The calculated amount of metal powder, PMMA, PEG, paraffin wax and stearic acid were weighed and mixed together. The mixing was carried out at $160^{\circ} \mathrm{C}$ and $40 \mathrm{rpm}$ to attain a homogeneous distribution of the powder particles and binder in feedstock. After thorough mixing, the mixture was first dried in air at ambient temperature for 2 hours and then in an oven at a temperature of $50^{\circ} \mathrm{C}$ for 1 hour. After compounding the feedstock was allowed to cool to at ambient temperature and then granulated in a rotary feedstock granulator. The SEM micrograph of SS316L powder used for study is shown in Figure 1. 


\section{Production of Test Specimen}

A four-cavity mould was specifically designed and made with cavities in accordance with MPIF Standard 50 and ASTM Standard E8-98. The impact specimen geometry needed for this study was a $5 \mathrm{~mm}$ x $10 \mathrm{~mm}$ x $55 \mathrm{~mm}$ unnotched bar. Using the known shrinkage factor for the given feedstock, the impact bars were molded to produce oversize green parts as shown in Figure 2. The subsequent processing produced parts with the final dimensions as specified in MPIF Standard 59 [14]. Either no machining or very fine machining was needed to prepare the Charpy impact bars for testing. The green parts and sintered parts are shown in Figure 2 and Figure 3 respectively. The final parts shown in Figure 4 were used to find the final density.

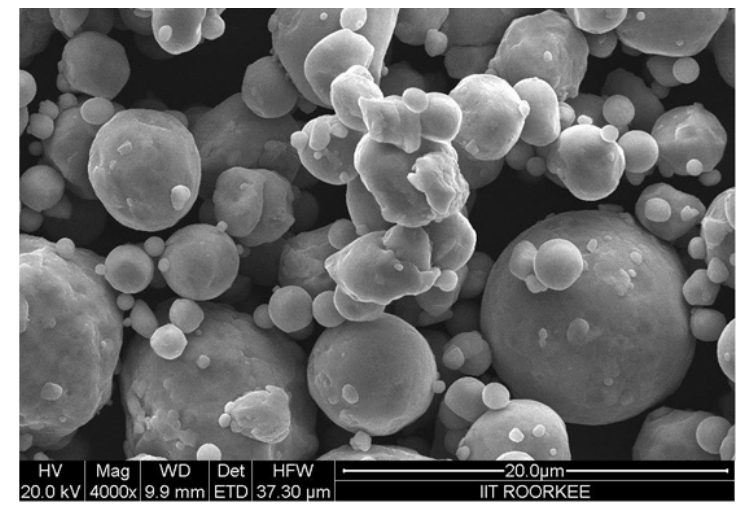

Figure 1: SEM Micrographs of SS316L Powder used for Study.

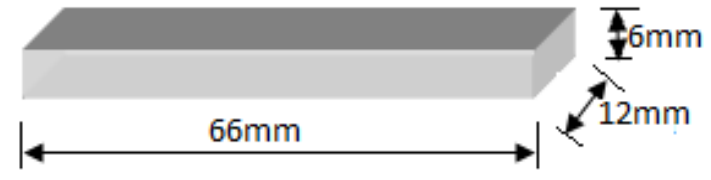

Figure 2: MPIF 59 Based Impact Test Bar (Specimen Size Before Sintering).

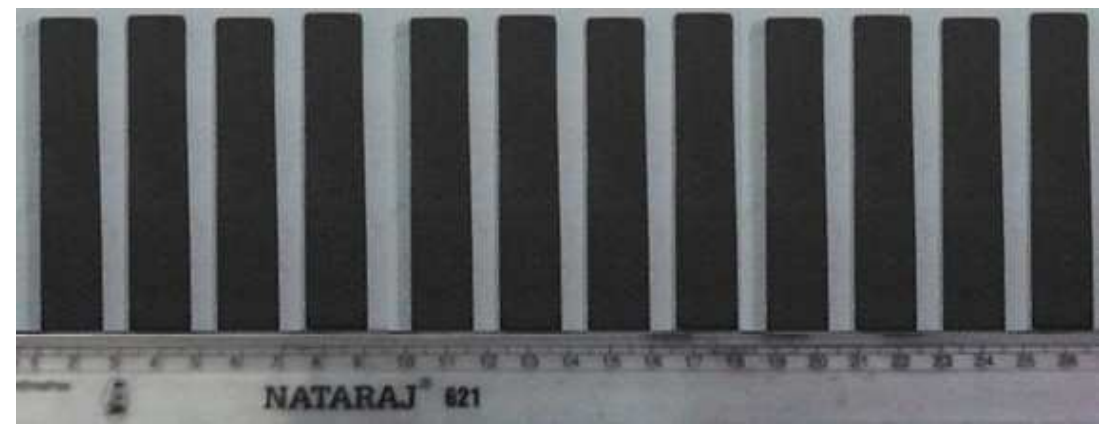

Figure 3: The Samples Produced by Injection Moulding.

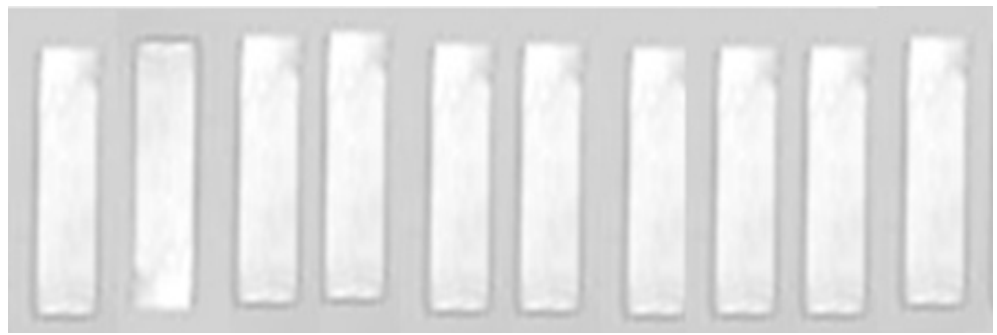

Figure 4: The Samples Produced After Sintering. 


\section{Injection Moulding Procedure}

Injection moulding process comprises of heating of the feedstock material to binder melting temperature, forcing the molten material into the mould cavities, holding at high pressure, then cooling and ejection of the molded parts out of the mould cavity. In the experimental work, a Demag injection moulding machine with microprocessor control was used. On the machine, the injection pressure, injection temperature, mould temperature, holding pressure, injection speed, holding time and cooling time were set at the desired values. Since, the powder loading is an external factor; it is not to be taken care by the machine control. Each set of values was repeated five times to make samples at each processing conditions after the machine has come to smooth functioning. All the test parts were produced by using only virgin feedstock.

\section{Debinding Procedure}

The green parts were debound through the solvent and thermal debinding techniques to remove the binders effectively. In the first step, solvent extraction was used to extract out the PEG and paraffin wax from the green parts. The green specimens were immersed in high temperature distilled water with continuous stirring. The leached specimens were then dried in an oven to remove the remains of water completely and then cooled it again. The second step, referred to as thermal debinding was used to remove the PMMA and stearic acid after solvent debinding. The leached specimens were put into an alumina tray in which the surrounding space was filled with alumina powder to avoid any distortion of the specimens. The thermal debinding was achieved in a vacuum furnace. The brown part was allowed for a slow cooling to ambient temperature $\left(27^{\circ} \mathrm{C}\right)$ to release the residual stress from the part.

\section{Sintering Procedure}

The objective of this experiment was to find the significant factors in sintering process, their contribution and optimised levels. As good quality parts with desired mechanical properties can be ensured only after proper sintering, an analysis of variance (ANOVA) is utilized to identify the significant level of each variable.

If full factorial design is used in all the four factors with four levels then it will develop 256 combinations. But, the modified $\mathrm{L}_{16}$ can be used to accommodate four factors with four levels is based on the concept for conversion, which in turn dependent upon the concept of degrees of freedom [8]. It is notable that a two level OA has one piece of information associated with it: the comparison of the average of all the first level tests compared to the averages of all of the second level tests. While, a four level factor has three pieces of information concerning with it: the first- to second level effect, the second to third level effect, and the third to fourth level effect [22]. Using the investigations [11,20] and the expertise of the sintering process five main parameters were considered to study. The processing variables and their values at different levels are shown in Table 5.

The experimental results were converted in $\mathrm{S} / \mathrm{N}$ values for optimization of parameters. The $\mathrm{S} / \mathrm{N}$ ratio (higher the better) is used for analysis. To find the confidence level and variance of the data ANOVA is used for effective output. The confidence level is measured from the variance of each parameter. In order to verify a confirmation test was conducted within the range of optimum performance calculation. 
Table 5: Controllable Process Parameters for Sintering of Specimens

\begin{tabular}{|l|c|c|c|c|c|}
\hline \multicolumn{1}{|c|}{ Process Parameters } & Symbol & Level 1 & Level 2 & Level 3 & Level 4 \\
\hline Sintering temperature $\left({ }^{\circ} \mathrm{C}\right)$ & $\mathrm{Ts}$ & 1260 & 1300 & 1340 & 1380 \\
\hline Heating rate $\left({ }^{\circ} \mathrm{C} / \mathrm{min}\right)$ & $\mathrm{T}_{\mathrm{h}}{ }^{\circ}$ & 4 & 8 & 12 & 16 \\
\hline Sintering time $(\mathrm{minutes})$ & $\mathrm{ts}$ & 60 & 80 & 100 & 120 \\
\hline Cooling rate $\left({ }^{\circ} \mathrm{C} / \mathrm{min}\right)$ & $\mathrm{T}_{\mathrm{s}}{ }^{*}$ & 5 & 10 & 15 & 20 \\
\hline Sintering atmosphere & $\mathrm{p}$ & Vacuum & $\mathrm{N} 2$ & -- & --- \\
\hline
\end{tabular}

\section{RESULTS}

The calculated values of $\mathrm{S} / \mathrm{N}$ ratio to access the variation in density due to variation in sintering parameters are shown in Table 6. The analysis of variance made by using S/N ratio to find the significant factors and their contribution is expressed in Table 7. From Table, it can be observed that four out of the five factors are the significant factors. Since, there is one insignificant factor, so pooling is required. The sintering temperature has a contribution of $14.37 \%$ at a confidence level of $95 \%$, heating rate has a contribution of $14.65 \%$ at a confidence level of $95 \%$, sintering time has a contribution of $59.58 \%$ at a confidence level of $99 \%$, cooling rate has a contribution of $10.70 \%$ with a confidence level of $95 \%$, and sintering atmosphere is observed to be insignificant factor for density attained by the specimen.

The optimum level of parameters can be obtained by selecting the highest values of $\mathrm{S} / \mathrm{N}$ ratios from respective column in Table 6. The optimum level for Density occurs at $\left(\mathrm{T}_{\mathrm{s}}\right)_{4}\left(T_{\mathrm{d}}^{\mathrm{s}}\right)_{3}\left(\mathrm{t}_{\mathrm{s}}\right)_{4}\left(T_{\varepsilon}^{\mathrm{s}}\right)_{2}(p)_{2}$. From Table 6 it can also be noted from the rank of parameters that the variation in the $\mathrm{S} / \mathrm{N}$ ratio value with the change in the value of the parameter is maximum for sintering time and minimum for sintering atmosphere.

Table 6: Response Table for Signal to Noise Ratios (Larger is Better)

\begin{tabular}{|c|c|c|c|c|c|}
\hline Level & $\mathbf{T}_{\mathbf{s}}$ & $\boldsymbol{T}_{\boldsymbol{h}}^{*}$ & $\mathbf{t}_{\mathbf{s}}$ & $\boldsymbol{T}_{\boldsymbol{c}}^{*}$ & $\boldsymbol{p}$ \\
\hline 1 & 17.41 & 17.37 & 17.24 & 17.46 & 17.46 \\
\hline 2 & 17.42 & 17.46 & 17.49 & 17.51 & 17.46 \\
\hline 3 & 17.44 & 17.55 & 17.53 & 17.49 & -- \\
\hline 4 & 17.57 & 17.45 & 17.56 & 17.37 & -- \\
\hline Delta & 0.16 & 0.18 & 0.32 & 0.14 & 0.00 \\
\hline Rank & 3 & 2 & 1 & 4 & 5 \\
\hline
\end{tabular}

Table 7: Analysis of Variance using S/N Ratios for Density

\begin{tabular}{|c|c|c|c|c|c|c|c|}
\hline $\begin{array}{l}\text { Factors/ } \\
\text { Source }\end{array}$ & $\begin{array}{c}\text { DOF, } \\
v\end{array}$ & $\begin{array}{l}\text { Sums of } \\
\text { squares }\end{array}$ & $\begin{array}{c}\text { Variance, } \\
\mathbf{V}_{\mathbf{n}} \\
\end{array}$ & $\begin{array}{l}\text { Variance } \\
\text { Ratio, } \mathbf{F}_{\mathbf{n}}\end{array}$ & $\begin{array}{c}\text { Significance } \\
\text { Level, } \alpha\end{array}$ & $\begin{array}{l}\text { Pure Sum } \\
\text { Square }\end{array}$ & $\begin{array}{c}\text { Contribution, } \\
\mathbf{P} \text { in } \%\end{array}$ \\
\hline $\mathbf{T}_{\mathrm{s}}$ & 3 & 0.06378 & 0.02126 & 107.38 & 0.05 & 0.06318 & 14.37 \\
\hline$T_{h}$ & 3 & 0.06501 & 0.02167 & 109.45 & 0.05 & 0.06441 & 14.65 \\
\hline $\mathbf{t}_{\mathrm{s}}$ & 3 & 0.26249 & 0.08749 & 441.88 & 0.01 & 0.26189 & 59.58 \\
\hline$T_{c}^{*}$ & 3 & 0.04763 & 0.01588 & 80.19 & 0.05 & 0.04703 & 10.70 \\
\hline$p$ & (1) & 0.00007 & & & & & \\
\hline $\begin{array}{c}\text { Residual } \\
\text { Error }\end{array}$ & 3 & 0.000594 & 0.000198 & & & & 0.70 \\
\hline Total & 15 & 0.43953 & & & & & 100 \\
\hline
\end{tabular}

The required response the analysis of the trend of performance characteristics with respect to variation of the controllable factor are shown in Figure 5 and Table 6. 


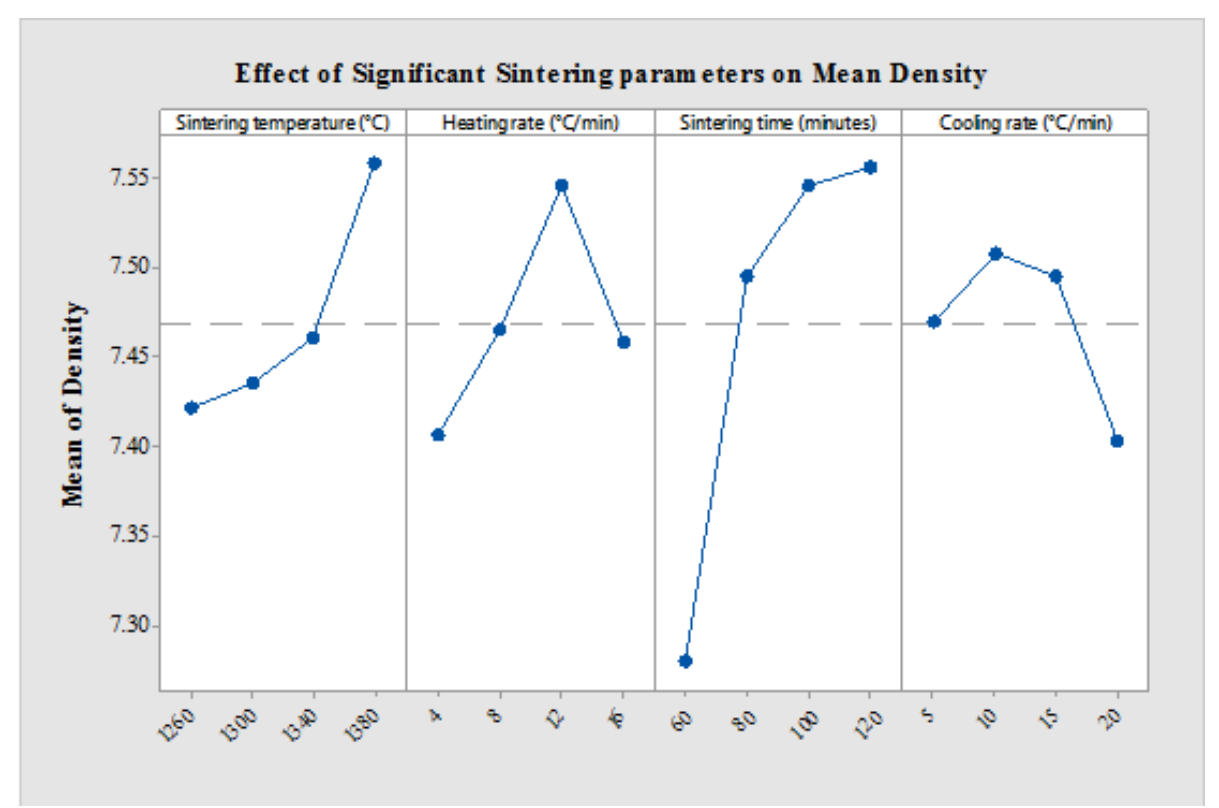

Figure 5: Main Effects Plot for Mean Values of Density due to Controlled Sintering Parameters.

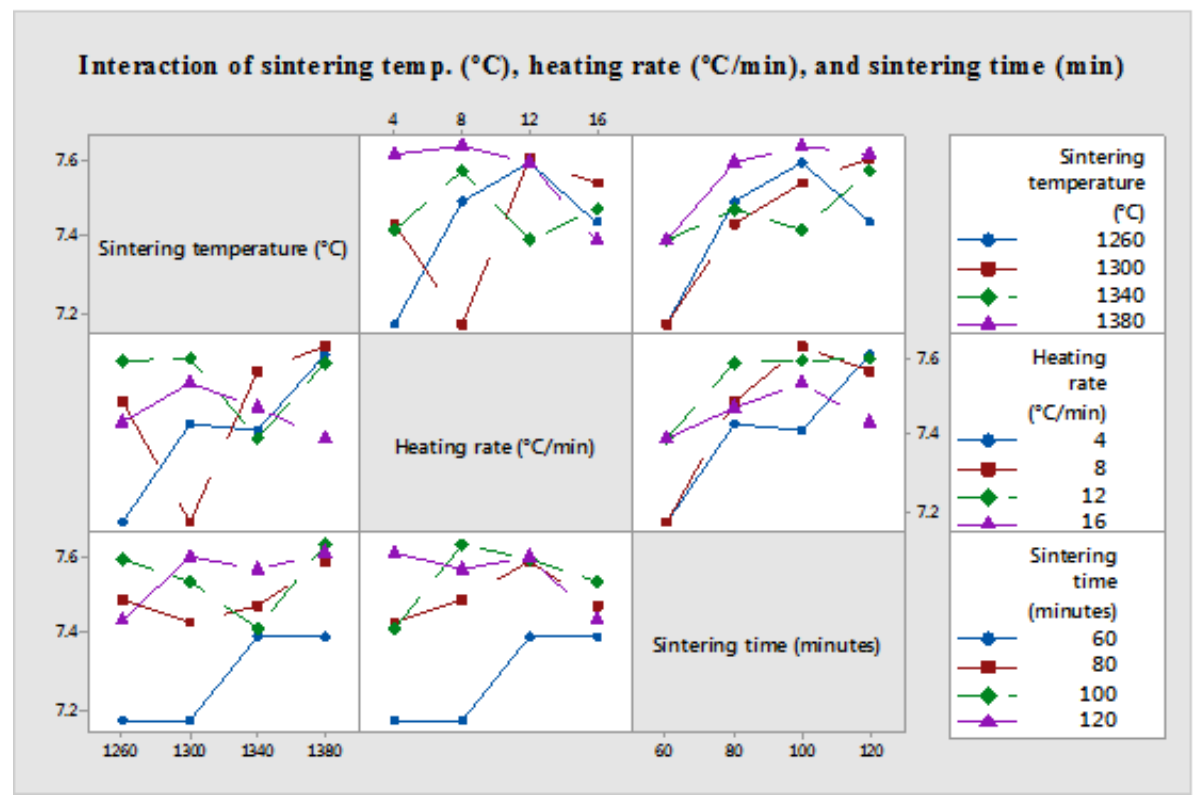

Figure 6: Interaction Pot for Sintering Temperature $\left({ }^{\circ} \mathrm{C}\right)$, Heating Rate $\left({ }^{\circ} \mathrm{C} / \mathrm{min}\right)$, and Sintering Time (Minutes). 


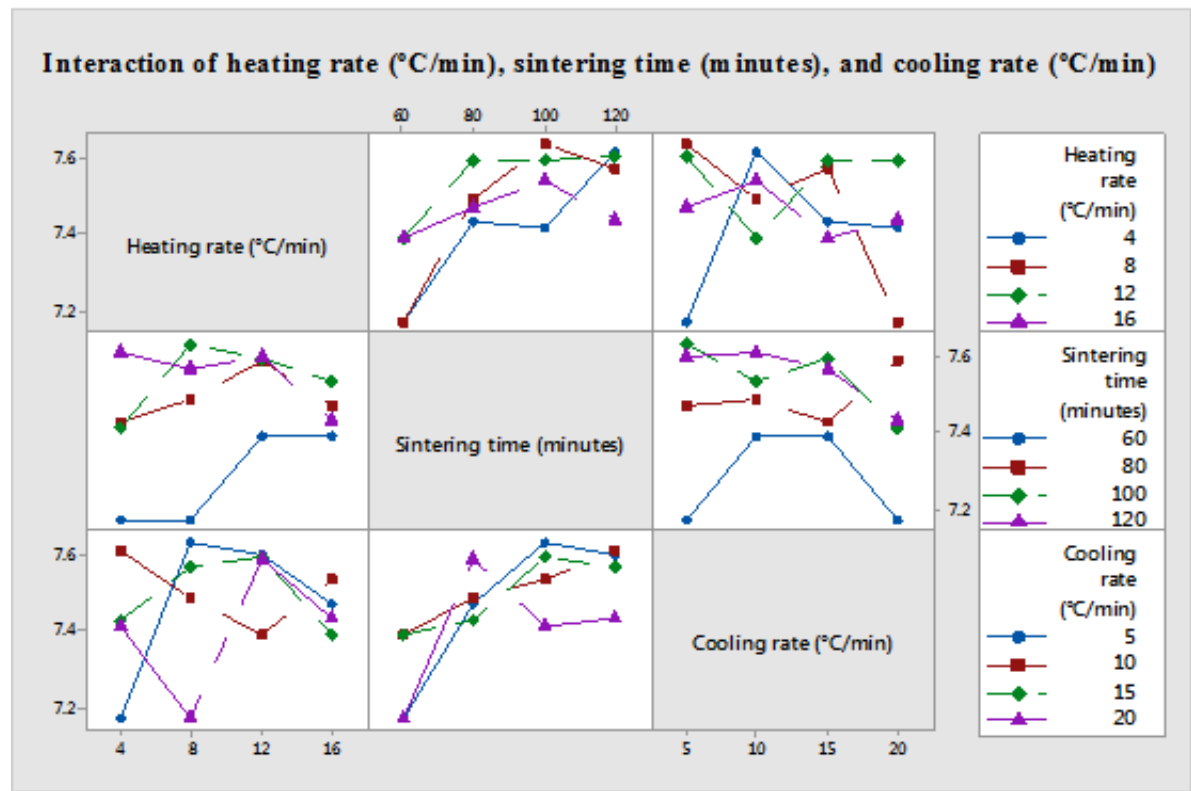

Figure 7: Interaction Plot for Heating Rate $\left({ }^{\circ} \mathrm{C} / \mathrm{min}\right)$, Sintering Time (Minutes), and Cooling Rate $\left({ }^{\circ} \mathrm{C} / \mathrm{min}\right)$.

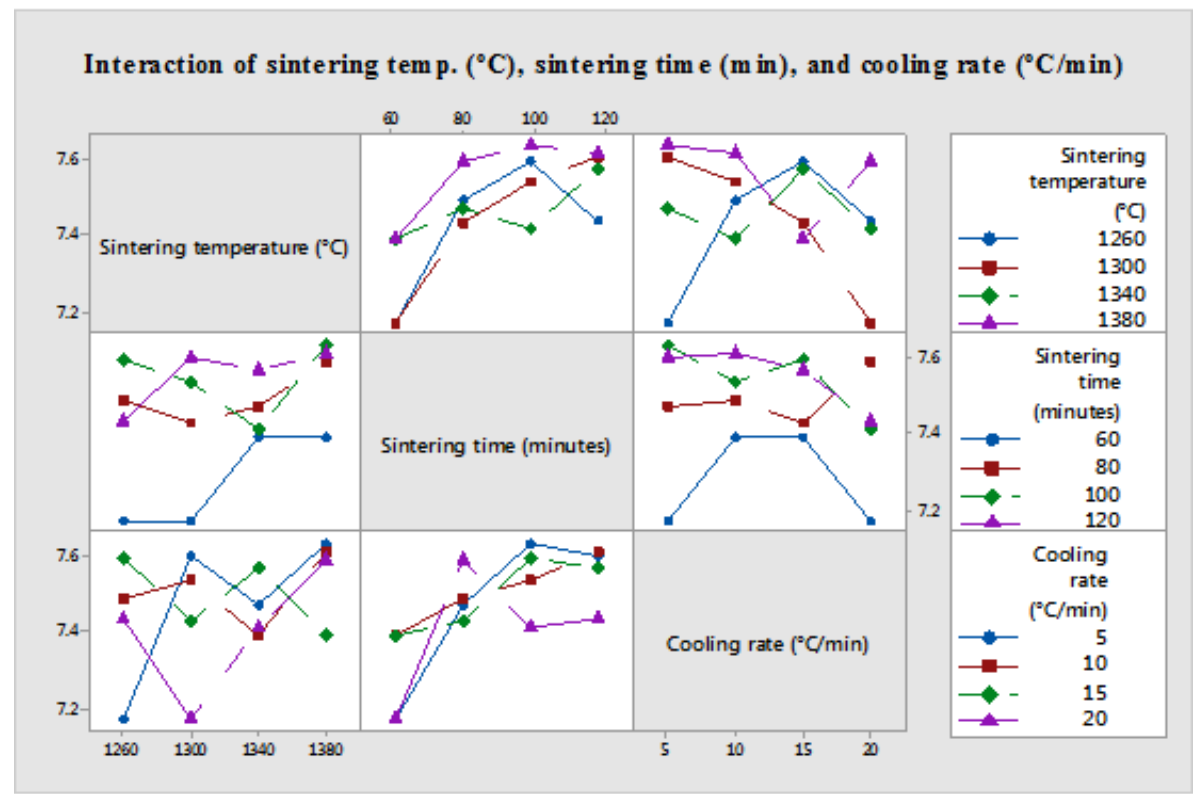

Figure 8: Interaction Plot for Sintering Temperature $\left({ }^{\circ} \mathrm{C}\right)$, Sintering Time (Minutes), and Cooling Rate $\left({ }^{\circ} \mathrm{C} / \mathrm{min}\right)$.

Table 8: Factor Levels for Prediction

\begin{tabular}{|c|c|c|c|c|}
\hline $\begin{array}{c}\text { Sintering } \\
\text { temperature }(\mathbf{C})\end{array}$ & $\begin{array}{c}\text { Heating rate } \\
(\mathbf{C} \text { C/min) }\end{array}$ & $\begin{array}{c}\text { Sintering time } \\
\text { (minutes) }\end{array}$ & $\begin{array}{c}\text { Cooling rate } \\
\text { ( } \mathbf{C} / \mathbf{m i n})\end{array}$ & $\begin{array}{c}\text { Sintering } \\
\text { atmosphere }\end{array}$ \\
\hline 1380 & 12 & 120 & 10 & Nitrogen \\
\hline
\end{tabular}

\section{CONFIRMATION TEST}

Since, the sintering temperature, heating rate, sintering time, and cooling rate are the significant factors; the optimum value of density will depend on all these factors and could be estimated by equation (1) at the optimum levels shown in Table 8 .

$$
\mu_{\rho}=\bar{T}+\left[\left(\mathrm{T}_{\mathrm{s}}\right)_{4}-\bar{T}\right]+\left[\left(\bar{T}_{\hat{h}}^{\mathrm{a}}\right)_{3}-\bar{T}\right]+\left[\left(\mathrm{t}_{\mathrm{s}}\right)_{4}-\bar{T}\right]+\left[\left(T_{c}^{\bar{a}}\right)_{2}-\bar{T}\right]
$$


Hence, the expected density at optimum condition is:

$\mu_{\rho}=7.558+7.546+7.556+7.508-(3 \times 7.4691)=7.7607 \mathrm{gm} \mathrm{cm}^{-3}$

The $95 \%$ confidence interval (CI) for the expected yield from the confirmation experiment can be calculated using equation (2) as follows:

$$
C I=\left(F_{\sigma}\left(\theta_{1}, \theta_{2}\right) F_{e}\left[\left(1 / n_{\text {efi }}\right)+(1 / r)\right]\right)^{1 / 2}
$$

Where,

$n_{\text {eff }}=(\mathrm{N} /(1+$ total degree of freedom of all factors used for estimating $\mu)$

$r=$ sample size for the confirmation experiment, $\mathrm{r} \neq 0 . F_{c e}\left(\vartheta_{1}, \vartheta_{2}\right)$ is the variance ratio of $\vartheta_{1}$ and $\vartheta_{2}$ at level of significance $\alpha$. The confidence level is $(1-\alpha), v_{1}$ is the degree of freedom of mean (equal to 1 ) and $v_{2}$ is the degree of freedom for the pooled error. Variance for pooled error is $V_{\varepsilon}$. The confidence interval indicates the maximum and minimum levels of the optimum performance.

$\mathrm{CI}=\{10.1 \times 0.000198[(1 / 6.15)+(1 / 5)]\}^{1 / 2}= \pm 0.02692$

Therefore, expected density at optimum condition $=7.4691 \pm 0.02692$

To confirm the prediction, another five samples were made at the recommended setting $\left(\mathrm{T}_{\mathrm{s}}\right)_{4}\left(T_{\mathrm{Z}}^{\mathrm{a}}\right)_{3}\left(\mathrm{t}_{\mathrm{s}}\right)_{4}\left(T_{\mathrm{c}}^{\mathrm{g}}\right)_{2}$ and $(p)_{2}$ as shown in Table 8. The results are shown in Table 9.

Table 9: Results of Confirmation Experiments

\begin{tabular}{|c|c|c|c|c|c|c|c|}
\hline \multirow{2}{*}{ Characteristic } & \multicolumn{5}{|c|}{ Replication at Optimum Process Parameters } & \multirow{2}{*}{ Average } & \multirow{2}{*}{$\begin{array}{c}\text { Minitab } \\
\text { predicted } \\
\text { value }\end{array}$} \\
\hline & $\mathbf{R 1}$ & $\mathbf{R 2}$ & $\mathbf{R 3}$ & R4 & R5 & & \\
\hline Density $\left(\mathrm{gm} \mathrm{cm}^{-3}\right)$ & 7.4501 & 7.5232 & 7.5863 & 7.5291 & 7.6844 & 7.5546 & 7.7582 \\
\hline
\end{tabular}

It is found that the average density obtained from the confirmation experiment is close to the mean of $95 \%$ confidence interval. From Table 9 it can also be noted that the experimental results are close to the predicted result by Minitab 17 software. The difference between measured and predicted values is about $2.69 \%$. The deviation occurs because the Minitab software uses linear regression model for prediction.

\section{CONCLUSIONS}

Sintering temperature is observed to be one of the significant process parameter of sintering process for final densification as visible from Table 7. When we study the effect of sintering temperature on densification of SS316L, it is observed that the densification of SS316L powder begins at sintering temperature of about $1260{ }^{\circ} \mathrm{C}$. The sintering begins slowly in the initial stage, but soon it causes rapid shrinkage in the intermediate stage; afterwards the shrinkage becomes much slower in the final stage to finish the sintering process [11]. At $1375^{\circ} \mathrm{C}$ the SS316L powder begins to melt so the bondage among the particles becomes week. But, contrary effects are observed in case of final density. The best results can be observed from Figure 6. The densification and changes in mechanical properties occur mainly in the heating period. Heating rate is also one of the significant process parameter of sintering process as observed from Tables 7 . It affects both the densification and final mechanical properties of the sintered part. From Figure 7, it can be observed that best densification occurs at a heating rate of $12^{\circ} \mathrm{C} / \mathrm{min}$. The sintering time is also a significant factor for densification and development of all 
the mechanical properties and has the highest contribution as observed from Tables 7. During this time at sintering temperature the closed pores continue to reduce or vanish and the grain size increase. The holding time of 120 minutes is appropriate for obtaining the final components with high density, as visible from Figure 8. The cooling rate is also a significant factor for densification and mechanical properties but its contribution is low as compared to other parameters as observable from Tables 7. It can also be noted from Figures 8, that slow cooling rate is desirable and good results are observed at a cooling rate of $10^{\circ} \mathrm{C} / \mathrm{min}$. The sintering atmosphere is an insignificant factor as observed from Tables 7 .

\section{ACKNOWLEDGEMENT}

The author would like to acknowledge the financial support and facilities provided by Noida Institute of Engineering and Technology, Greater Noida for this research work.

\section{REFERENCES}

1. German, R.M., and Bose, A. (1997). Injection Moulding of Metals and Ceramics. Metal Powder Industries Federation.

2. Berginc, B., Kampus, Z., and Sustarsic, B. (2006). The Use of Taguchi Approach to Determine the Influence of Injection Moulding Parameters on the Properties of Green Parts. Journal of Achievements in Materials and Manufacturing Engineering, 15; 63-70.

3. German, R.M. (1994). Homogeneity Effects on Feedstock Viscosity in Powder Injection Moulding. Journal of American Ceramic Society, 77 (1) 283-285.

4. Barriere, T., Liu, B., and Gelin, J.C.(2003). Determination of the Optimal Parameters in the Metal Injection Moulding from Experiments and Numerical Modeling. Journal of Materials Processing Technology, 143-144; 636-644.

5. Heaney, D.F., Zauner, R., Binet, C., Cowan, K., and Piemme, J.(2004). Variability of Powder Characteristics and their Effect on Dimensional Variability of Powder Injection Moulded Components. Powder Metallurgy, 47 (2) 145-150.

6. Wei, W.C.J., Wu, R.Y., and Ho, S.J. (2000). Effects of Pressure Parameters on Alumina Made by Powder Injection Moulding. Journal of European Ceramic Society, 20; 1301-1310.

7. Li, Y., Li, L., and Khalil K.A. (2007). Effect of Powder Loading on Metal Injection Moulding Stainless Steel. Journal of Materials Processing Technology, 183; 432-439.

8. Ross, P.J. (1996). Taguchi Techniques for Quality Engineering. Tata McGraw Hill.

9. Roy, R.K. (2001). Design of Experiments Using the Taguchi Approach. John Wiley \& Sons.

10. Zu, Y.S., and Lin, S.T. (1997). Optimising the Mechanical Properties of Injection Molded W-4.9\% Ni-2, $1 \%$ Fe in Debinding. Journal of Materials Processing Technology, 71; 337-342.

11. Ji, C.H., Loh, N.H., Khor, K.A., and Tor, S.B. (2001). Sintering Study of Stainless Steel Metal Injection Moulding Parts using Taguchi Method: Final Density. Materials Science \& Engineering, A311; 74-82.

12. Tseng, W.J. (1998) Statistical Analysis of Process Parameters Influencing Dimensional Control in Ceramic Injection Moulding. Journal of Materials Processing Technology, 79; 242-250.

13. Jamaludin, K.R., et.al. (2008). Analysis of Variance on the Metal Injection Moulding Parameters using a Bimodal Particle Size Distribution Feedstock. Proceedings of International Conference on Mechanical \& Manufacturing Engineering.

14. MPIF (2002). Method for Determination of Charpy Impact Energy of Unnotched Metal Injection Molded Test Specimens. Standard 59, Standard Test Methods for Metal Powders and Powder Metallurgy Products. 
15. Roy, R.K., (1990). A Primer on the Taguchi Method. Competitive Manufacturing Series, Van Nostrand Reinhold.

16. German R.M. (1996). Sintering Theory and Practice. Wiley, New York.

17. Nayar, H.S., and Wasiczko B. (1990). Nitrogen Absorption Control during Sintering of Stainless Steel Parts. Metal Powder Report, 45 (9) 611-614.

18. Talacchia, S., et al. (1993). Increasing Sintering Gate and Avoiding Grain Growth in High Speed Steels by Sintering in Nitrogen Rich Atmospheres. Powder metallurgy, 36 (4) 275-280.

19. Urrutibeaskoa, I., and Urcola J.J. (1993). Sintering Behaviour of Grade M Water Atomised High Speed Steel Powders Under Vacuum and Nitrogen Rich Atmosphere. Powder metallurgy, 36 (1) 47-54.

20. Song, J., et al. (2006). Experiments and Numerical Modelling of Solid State Sintering for 316L Stainless Steel Components. Journal of Materials Processing Technology, 177 (1) 352-355.

21. Li, S., et al. (2003). Influences of Sintering Atmospheres on Densification Process of Injection Moulded Gas Atomised $316 L$ Stainless Steel. Powder metallurgy, 46 (3) 241-245.

22. Taguchi G. and Konishi S. (1987). Taguchi methods, orthogonal arrays and linear graphs, tools for quality, American Supplier Institute.

23. Rajendrsinh Darbar \& Prajesh M. Patel, "Optimization of Fused Deposition Modeling Process Parameter for Better Mechanical Strength and Surface Roughness “, International Journal of Mechanical Engineering (IJME), Vol. 6, Issue 6,pp. 7 $-18$

24. Mohammed Yunus \& Mohammad S.Alsoufi , "A Statistical Analysis of Joint Strength of Dissimilar Aluminium Alloys Formed by Friction Stir Welding Using Taguchi Design Approach, Anova for the Optimization of Process Parameters “, IMPACT: International Journal of Research in Engineering \& Technology (IMPACT: IJRET), Vol. 3, Issue 7, pp.63-70

25. I. D. Awasthi\& Mukesh Kumar Panth, "Effect of Interval between two Estimation Techniques on the Similarities and Differences among Envy and Jealousy “, BEST: International Journal of Humanities, Arts, Medicine and Sciences (BEST: IJHAMS), Vol. 4, Issue 2, pp. 89- 100

26. Digvijay Kushwaha, Raiv Ranjan, Vijendra Kumar Kushawaha \& Mohammad Tariq, "Evaluation and Optimization of Cutting Parameters for Turning of En-8 Steel: A Taguchi Approach “, International Journal of Mechanical Engineering (IJME), Vol. 6, Issue 4,pp. 35-44 